\title{
Description d'un Purpuricenus nouveau du Japon
}

[Col. Cerambycidae]

par L. Villakd.

Purpuricenus Ritsemai, n. sp. - Noir; corselet et élytres rouge vermillon, tachés de noir. - Long. 22 mill., larg. 7 mill.

Tète noire, largement concave entre les tubercule antennifères et marquée, en arrière du front, d'un petit relief brillant. - Antennes noires, plus longues que les élytres; $1^{\mathrm{er}}$ article en massue, grossièrement ponctué; les articles suivants à ponctuation plus fine, couverts d'une très fine et courte pubescence grisâtre; extrémité de chaque article portant quelques longs cils noirs. - Corselet rouge en dessus, rouge en dessous jusqu'au prosternum, sauf un étroit bandeau noir à son bord antérieur; surface à ponctuation forte et rugueuse, ornée de cinq taches noires, la première étroite, allongée sur la ligne médiane, plus près et un peu en avant de l'écusson; les quatre autres plus grandes, placées deux par deux de chaque côté (la surface occupée par les taches plus fortement rugueuse que le restant du corselet). - Écusson noir velouté, en triangle aigu, étroit et long. - Élytres rouges, un peu plus larges que le corselet, parallèles, arrondis ensemble à l'extrémité, à ponctuation rugueuse à la base, diminuant très sensiblement à partir du second quart; ornés, de chaque côté, $1^{\circ}$ d'une tache noire subcarrée, située entre le bas du calus huméral et la suture, un peu plus près de cette dernière que de la marge externe; $2^{\circ}$ d'une grande tache noir velouté, commune aux deux élytres, naissant un peu avant le milieu et s'arrêtant au cinquième de leur longueur. Cette tache, d'abord étroite et parallèle le long de la suture, se dilate ensuite de chaque côté de son extrémité inférieure en un lobe ponctiforme dirigé en dehors, mais n'atteignant pas la marge. - Mètasternum pointillé, ridé. Abdomen à ponctuation plus fine, couvert d'une longue villosité grise, clairsemée. Prosternum et més os ternum épineux. - Pattes noires, à ponctuation rugueuse.

Patrie : Nagato (Japon).

Dédié à M. C. Ritsema, en remerciment de ses nombreuses obligeances à mon égard.

Ce Purpuricenus ressemble beaucoup, au premier abord, au P. dalmatinus Sturm, près duquel il doit se placer, mais la différence de ponctuation, ses pro- et mésosternum épineux, sans parler d'autres caractères de moindre importance, l'en séparent aisément. 


\section{$2 \mathrm{BHL}$ Biodiversity Heritage Library}

1913. "Description d'un Purpuricenus nouvean du Japon." Bulletin de la Société entomologique de France 1913, 237-237.

https://doi.org/10.5962/bhl.part.16286.

View This Item Online: https://www.biodiversitylibrary.org/item/36377

DOI: https://doi.org/10.5962/bhl.part.16286

Permalink: https://www.biodiversitylibrary.org/partpdf/16286

\section{Holding Institution}

Smithsonian Libraries

\section{Sponsored by}

Smithsonian

\section{Copyright \& Reuse}

Copyright Status: NOT_IN_COPYRIGHT

This document was created from content at the Biodiversity Heritage Library, the world's largest open access digital library for biodiversity literature and archives. Visit BHL at https://www.biodiversitylibrary.org. 